\title{
Consumo de alimentos orgânicos: um estudo exploratório
}

\author{
Consumption of organic foods: an exploratory study
}

\section{Resumo}

Este artigo objetivou compreender o comportamento do consumidor de alimentos orgânicos respondendo as questões: quais os hábitos alimentares diários e como o alimento orgânico é observado pelos consumidores. Utilizou-se a teoria do comportamento do consumidor e pesquisas sobre 0 consumo de alimentos orgânicos. De caráter exploratório, neste trabalho foram realizados dois grupos focais por meio da técnica de análise de conteúdo. O primeiro grupo focal de consumidores de alimentos orgânicos demonstrou conscientização sobre a importância do alimento orgânico, ocorrendo inclusive relações de socialização. Já o grupo focal de consumidores de alimentos tradicionais percebeu este tipo de alimento como saudável, contudo, não apresentou a consciência do conceito deste tipo de produto e de seus benefícios.
\end{abstract}

Danilo de Oliveira Sampaio ${ }^{\mathrm{I}}$

Marlusa Gosling ${ }^{2}$

André Francisco Alcântara Fagundes ${ }^{3}$

Caissa Veloso e Sousa ${ }^{4}$

Palavras-chave: Alimentos orgânicos, Comportamento do consumidor, Grupos focais.

\begin{abstract}
This article aimed to understand the consumer behavior of organic foods answering the questions: what are the daily eating habits and how organic food is seen by consumers. We used the theory of consumer behavior and research on the consumption of organic food. Exploratory, this study conducted two focus groups using the technique of content analysis. The first focus group of consumers of organic food showed awareness of the importance of organic food, mainly the relations of socialization. Have a focus group of consumers of traditional foods perceived this type of food as healthy, however, showed no awareness of the concept of this type of product and its benefits.
\end{abstract}

Keyword: Organic food, Consumer behavior, Focus groups.

\footnotetext{
1 danilo.sampaio@ufjf.edu.br, Brasil. Professor Adjunto da Universidade Federal de Juiz de Fora - UFJF. Doutor em Administração pela Universidade Federal de Minas Gerais - UFMG. Rua José Lourenço Kelmer, s/n, Campus Universitário, CEP: 36036-900 - Juiz de Fora, MG - Brasil.

2 mg.ufmg@gmail.com, Brasil. Professora Associada da Universidade Federal de Minas Gerais - UFMG. Doutora em Administração pela Universidade Federal de Minas Gerais - UFMG. Av. Antônio Carlos, 6627, Pampulha, CEP: 31270-901 Belo Horizonte, MG - Brasil

3 fagundesandre@yahoo.com.br, Brasil. Professor Titular da Universidade Federal de Juiz de Fora - UFJF. Doutorando em Administração na Universidade Federal de Minas Gerais - UFMG. Rua José Lourenço Kelmer, s/n, Campus Universitário, CEP: 36036-900 - Juiz de Fora, MG - Brasil.

${ }^{4}$ caissaveloso@yahoo.com.br, Brasil. Professora da Faculdade Novos Horizontes - FNH. Doutoranda em Administração na Universidade Federal de Minas Gerais - UFMG. Rua Alvarenga Peixoto, 1270, Santo Agostinho, CEP: 30180-121 - Belo Horizonte, MG - Brasil
}

Recebido em 22.05.2012

Aprovado em 27.02.2013

Revista Administração em Diálogo

ISSN 2178-0080

Programa de Estudos Pós-Graduados em Administração

Pontifícia Universidade Católica de São Paulo 


\section{Introdução}

Os alimentos orgânicos tem sido alvo de estudos por acadêmicos ligados a diferentes áreas, como Administração, Nutrição, Agroecologia, Economia, dentre outras, conforme apontam Soares (20IO) e Ceschim e Marchetti (2009). Os autores destacam como os principais temas estudados em relação ao alimento orgânico a questão da saúde, preservação ambiental, valorização da agricultura familiar, redução da contaminação dos alimentos e demanda de mercado. Ademais, pesquisas e reportagens sobre os possíveis benefícios do alimento orgânico são frequentes na área acadêmica e no cotidiano de uma sociedade que tende a se preocupar cada vez mais com a saúde (KRISCHKE; TOMIELLO, 2OO9; SOARES, 20I0; STEFANO; GODOY; RUPPENTHAL, 2OO7; WILLIAMSON, 2007).

Para o Research Institute of Organic Agriculture (FIBL, 2008) e a International Federation of Organic Agriculture (IFOAM, 2OIO) - instituições européias de fomento e pesquisa para o desenvolvimento da agricultura orgânica - a sustentabilidade dos alimentos orgânicos é um conceito central de interesse. Segundo dados do ano de 2008 há no mundo 35 milhões de terras agrícolas certificadas como de produção orgânica, sendo três milhões de hectares a mais do que registrado no ano de 2007. Os continentes que mais apresentaram aumento de terras orgânicas são a América Latina e a Europa, onde foi possível identificar I,4 milhões de produtores orgânicos.

De acordo com os dados de outra referência mundial no setor de orgânicos com sede em Londres, a Organic Monitor (2OII) - considerada uma das mais importantes fontes de relatórios de produção orgânica do mundo - a maior parte da produção mundial de orgânicos está na Oceania $(34,7 \%)$, seguida pela Europa (23,4\%) e América Latina (23 \%). Com relação às terras reservadas ao pasto, a Austrália representa a maior superfície orgânica certificada, com I2 milhões de hectares, seguida da Argentina com 4 milhões e da China com I,9 milhões. Para a Organic Monitor (2OIO), o mercado global de produtos orgânicos atingiu o valor de mais de 50 bilhões de dólares no ano de 2008 , apontando que os consumidores se encontram em sua maioria na América do Norte e Europa.

Apesar da relativa baixa produção de produtos orgânicos, pode-se considerar que o Brasil está despertando para o setor. De acordo com Penteado (2003), além das 
feiras específicas e de pequenos varejos especializados em produtos orgânicos, as grandes redes de varejo de autosserviço estão aderindo aos produtos orgânicos. Isto pode ser visto no caso das duas maiores redes de supermercados e hipermercados instaladas no Brasil - Pão de Açúcar e Carrefour - segundo a Associação Brasileira de Supermercados (ABRAS, 2OIO).

Tendo em vista o contexto do alimento orgânico em termos de importância econômica, social e ambiental, esta pesquisa tem como objetivo compreender melhor o comportamento do consumidor de alimentos orgânicos no Brasil por meio de dois grupos focais (GF). Dessa forma, empreende-se uma pesquisa exploratória buscando entender os principais aspectos desse consumo junto a consumidores de uma cidade do estado de Minas Gerais.

O artigo é composto, além desta introdução, pelo referencial teórico, aspectos metodológicos, análise dos dados da pesquisa e considerações finais.

\section{Referencial Teórico}

O referencial teórico é formado por dois temas de interesse para esta pesquisa: (i) o comportamento do consumidor; e (ii) o comportamento do consumidor de alimentos orgânicos.

\section{O comportamento do consumidor}

O estudo do comportamento do consumidor envolve estudos multidisciplinares de diferentes áreas científicas (MOWEN; MINOR, 2003). Para os autores, o estudo mercadológico do comportamento do consumidor é ligado principalmente a algumas áreas científicas como Administração, Psicologia, Economia, Antropologia e Sociologia.

Peter e Olson (2009) se apoiaram na definição que a American Marketing Association (AMA, 2OI2) apresenta sobre o comportamento do consumidor, "é a interação dinâmica entre afeto, cognição, comportamento e o ambiente pelo qual os seres humanos conduzem as trocas entre si”. Hawkins, Mothersbaugh e Best (2007) preferem ampliar a definição de comportamento do consumidor para além das trocas entre comprador e vendedor. Os autores relacionam o comportamento do consumidor às estratégias de marketing, sugerindo que o tema influencia os consumidores a possuírem 
um comportamento socialmente desejável. Para Blackwell, Miniard e Engel (2005) o comportamento do consumidor são as atividades em que as pessoas se engajam quando obtêm, consomem e dispõem de produtos e serviços. Para os autores, o comportamento do consumidor é um campo de estudo que foca nas atividades do consumidor.

Mowen e Minor (2003) relevam as funções de aquisição, consumo e disposição de produtos e serviços como ações dos consumidores, que interagem por meio de trocas e interesses. Os autores incluem em seus estudos três perspectivas de pesquisa sobre o comportamento do consumidor: (a) perspectiva da tomada de decisão para resolver um problema de forma racional; (b) perspectiva experimental mostra o consumidor envolvido em situações de compras por impulso e por busca de variedade, apontando sentimentos e emoções como variáveis importantes; e (c) perspectiva da influência comportamental, na qual o ambiente por meio de normas culturais, situações econômicas e pressões sociais impõem ao consumidor a atitude de compra sem considerar nem a racionalidade e nem os sentimentos.

Solomom (2002) defende os consumidores como atores no palco do mercado, possuindo diferentes papéis dependendo das circunstâncias envolvidas. Para o autor, o comportamento do consumidor é um processo contínuo que envolve questões de précompra, compra e pós-compra. Nesse sentido, Bagozzi, Gürhan-Canli e Priester (2002) consideram que o comportamento do consumidor é baseado nas trocas e benefícios mútuos entre os agentes envolvendo aspectos simbólicos fundamentais aos consumidores. Os autores destacam as atitudes e intenções comportamentais, pois estes aspectos estão diretamente ligados à intenção de compra, que deve ser considerada nas três fases destacadas por Solomon (2002)

Fishbein e Ajzen (1975) desenvolveram considerando as ações racionais baseadas nas atitudes comportamentais das pessoas. Ajzen (I99I), com a Teoria do Comportamento Planejado (TCP), comenta que a atitude do consumidor e a norma subjetiva são fatores chaves da intenção de comportamento, atentando que de acordo com essa teoria o controle comportamental percebido também impacta na intenção e, consequentemente, pode impactar o comportamento do indivíduo.

$\mathrm{Na}$ teoria do comportamento do consumidor, alguns pesquisadores propõem modelos estruturais para se compreender o comportamento dos consumidores. O 
modelo de Engel, Kollat e Blackwell (ı968) - denominado Modelo EKB - enfatiza fenômenos psicológicos, aspectos do ambiente e características individuais como influenciadores desse tipo de comportamento.

Posteriormente, o modelo EKB serviu como base para o Modelo EBM, derivado dos pesquisadores Engel, Blackwell e Miniard. Esse modelo, mais conhecido como modelo de processo de decisão do consumidor (PDC), tem como objetivo - segundo Blackwell, Miniard e Engel (2005, p. 73) - “[...] de analisar como os indivíduos ordenam os fatos e as influências para tomar decisões que são lógicas e consistentes para eles”. Destaca-se que o Modelo PDC possui sete estágios de tomada de decisão: (I) reconhecimento da necessidade; (2) busca de informações; (3) avaliação de alternativas pré-compra; (4) compra; (5) consumo; (6) avaliação pós-consumo; e (7) descarte.

Mesmo considerando-se a importância dos modelos de decisão de compra propostos por importantes autores, deve-se destacar as particularidades intrínsecas ao consumo de produtos ou serviços específicos. Nesse preâmbulo, a seguir optou-se por apresentar estudos que tratam do consumo de alimentos orgânicos e suas características.

\section{Comportamento do consumidor de alimentos orgânicos}

Boa parte dos artigos científicos, Dissertações e Teses que tratam do comportamento do consumidor de alimentos orgânicos são de natureza exploratória e tratam de uma temática relacionada à preocupação com a saúde e o estilo de consumo. Nessas pesquisas observam-se relatos que citam valores dos consumidores desse tipo de produto em relação à saúde. Torna-ser relativamente comum encontrar nas conclusões desses estudos que o consumidor de orgânicos valoriza a saúde, pois ele acredita que esse tipo de alimentação possibilita uma melhor qualidade de vida e reforço nutricional (DEFRA, 2оIо; KRISCHKE; TOMIELLO, 2009; MENEZES; PADULA; CALLEGARO, 2007; PIMENTA; VILAS BOAS, 2008; WILLIAMSON, 2OO7).

Krischke e Tomiello (2009) buscaram em sua pesquisa identificar as motivações das escolhas dos consumidores por alimentos orgânicos. Os autores chegaram à conclusão de que os consumidores optam pelo alimento orgânico principalmente segundo algumas características: (a) vida saudável; (b) qualidade de vida; (c) confiança na marca; e (d) qualidade do produto. 
Archanjo, Brito e Sauerbeck (200I), Ceschim e Marchetti (2009) e Rucinski e Brandenburg (20O2), desenvolveram pesquisas estudando o perfil dos consumidores de alimentos orgânicos, e dentre algumas conclusões destacam-se que o consumidor de alimento orgânico valoriza o meio ambiente natural. Esses estudos apontam que os consumidores percebem as vantagens relativas dos orgânicos mesmo considerando a diferença de preços quando comparados aos alimentos convencionais. Como ponto de reflexão, as pesquisas apontam a falta de estratégias de marketing dos varejos, incluindo a ausência de experimentação dos produtos orgânicos dentro das lojas e a pouca informação para os consumidores referentes a esse tipo de produto.

Krischke e Tomiello (2009) sinalizam que o alimento orgânico está inserido em uma rede de símbolos ecológicos na qual a alimentação faz parte. Os autores sinalizam que os consumidores de orgânicos preocupam-se também com as embalagens dos produtos alimentícios, observando se as organizações utilizam embalagens reaproveitáveis. No mesmo sentido, Archanjo, Brito e Sauerbeck (200I) também buscaram compreender qual o valor simbólico atribuído ao alimento orgânico por parte dos consumidores curitibanos. As autoras concluíram que a produção e o consumo de alimentos orgânicos fazem parte de um movimento que propõem mudanças além do comportamento alimentar. A pesquisa relata que o consumidor de orgânicos aponta este tipo de alimento como algo que venha prevenir e curar doenças, assumindo um valor simbólico de medicamento, por meio do qual se estabelece uma vida mais saudável.

Cuperschmid e Tavares (2002, p. o6) explicam que "o consumidor verde é aquele indivíduo que procura adotar atitudes e comportamentos de compra coerente com a conservação dos ecossistemas”. Os autores citam que o consumidor de alimento orgânico pode ser considerado um consumidor verde, pois este tem conhecimento sobre a importância da saúde ligada à alimentação.

O meio ambiente também é citado pelos consumidores de alimentos orgânicos do interior estado do Rio Grande do Sul, que destacam a importância dessa característica no momento de optarem por escolher esse tipo de alimento (ZAMBERLAN; BÜTTENBENDER; SPAREMBERGER, 2006). Ainda considerando esse aspecto, Smith, Lin e Huang (2009) apontam que os consumidores estadunidenses citam o alimento orgânico como aquele tipo de alimento específico de uma agricultura 
sustentável, pois além de preservar o meio ambiente esse tipo de produção tende a respeitar a biodiversidade integrada que é formada por plantas e animais.

Para Stefano, Godoy e Ruppenthal (2007), mesmo não havendo dados científicos que comprovem maior valor nutricional dos alimentos orgânicos, a percepção dos consumidores deste tipo de alimento é de que estes possuem qualidade superior se comparados aos alimentos não orgânicos. Os autores verificaram que a agricultura orgânica contribui para a preservação do meio ambiente e da saúde humana, além de gerar novos empregos no campo e nas cidades.

Conforme apontado por Cuperschmid e Tavares (2002), Rucinski e Brandenburg (2002) apontaram no seu estudo que o consumidor de alimento orgânico internaliza o movimento a favor da ecologia e possui consciência de preservação do meio ambiente, fato este que foi verificado quando o consumidor revelou que está disposto a pagar um valor mais elevado para dispor do alimento orgânico. Seguindo essa mesma linha, outras pesquisas verificaram que os consumidores de alimento orgânico estão dispostos a pagar um sobrepreço - disposição em pagar de Io\% a 20\% a mais do que os alimentos tradicionais - para terem em suas mesas uma melhor qualidade de alimento (PIMENTA; SENA; MOURA et al., 2Oo9; RUCINSKI; BRANDENBURG, 2OO2; ZAMBERLAN; BÜTTENBENDER; SPAREMBERGER, 2OO6).

Coltro (2006) encontrou as mesmas informações sobre o preço conforme Pimenta, Sena e Moura et al. (2009). Segundo o autor, o consumidor de alimentos orgânicos reconhece o valor agregado deste produto e está disposto a pagar a mais para consumi-lo. Observando ainda a variável preço, contudo considerando a renda do consumidor de alimentos orgânicos, Krischke e Tomiello (20o9) verificaram que este tipo de consumidor possui poder aquisitivo acima da média nacional - 45, ,\% dos consumidores de orgânico têm renda acima de doze salários mínimos ao mês.

A variável saúde foi apontada em diferentes estudos como sendo importante na decisão de escolha do consumidor de alimento orgânico. Segundo Krischke e Tomiello (2009), este tipo de consumidor é exigente em termos de qualidade e consciente em relação aos danos e aos riscos que os agrotóxicos utilizados nos alimentos tradicionais podem causar à saúde humana e animal. Pimenta, Sena e Moura et al. (20o9) corroboram com essa conclusão, ademais os autores constataram que $33 \%$ dos consumidores desse 
tipo de produto se dizem compradores frequentes, e que $82,6 \%$ afirmam que o alimento tradicional possui agrotóxico e fazem mal à saúde, enquanto que a opção pelo alimento orgânico é mais saudável.

Utilizando a metodologia de escalonamento de valores, ou laddering, em feiras livres de alimentos orgânicos na cidade de Belo Horizonte-MG, Vilas Boas, Sette e Brito (2006) verificaram que os consumidores desses produtos prezam pelo cuidado com a saúde pessoal e familiar, sendo orientado por valores como longevidade, tranquilidade e felicidade. Menezes, Padula e Callegaro (2007) também obtiveram resultados semelhantes, uma vez que a pesquisa empreendida pelos autores apontou que o sabor, cor e textura estão ligadas a uma melhor saúde, na opinião de consumidores de vinhos orgânicos.

Outra pesquisa sobre o comportamento dos consumidores de alimento orgânico baseada em valores foi apresentada por Pimenta e Vilas Boas (2008). Os autores identificaram na cidade de Uberlândia-MG evidências que confirmam a demanda dos consumidores por frutas, legumes e verduras orgânicas segundo a estrutura de atributos, consequências e valores para atender a teoria de meios e fins. Nessa pesquisa os consumidores foram entrevistados por meio do mapa hierárquico de valores.

Algumas pesquisas destacam a importância da variável qualidade para o consumidor de alimentos orgânicos, que se dispõe a pagar mais por um produto que tenha qualidade e que faça bem à saúde (COLTRO, 20o6; KRISCHKE e TOMIELLO, 2009; PIMENTA; VILAS BOAS, 2008; ZAMBERLAN; BÜTTENBENDER; SPAREMBERGER, 2006). Essa qualidade pode ser sinalizada pelo selo de certificação na embalagem do alimento orgânico, conforme aponta Coltro (2006). Neste sentido, o autor cita que o selo orgânico busca assegurar a qualidade do ambiente natural, a qualidade nutricional do alimento e biológica aos consumidores. Como resultado da pesquisa, o autor cita, dentre outros aspectos, a valorização da saúde humana e da qualidade do produto alimentício orgânico pelo consumidor.

Hoppe, Barcelos e Veira et al. (2OIO) desenvolveram uma survey com 446 consumidores de tomates orgânicos na cidade Porto Alegre-RS. Os autores aplicaram a Teoria do Comportamento Planejado (TCP), de Ajzen e Fishbein (2005), para compreender melhor como esses consumidores planejam suas compras. Os resultados 
da pesquisa mostram que as atitudes e a disponibilidade influenciam significativamente na intenção de consumo. Ou seja, quanto mais favorável a atitude e quanto maior a disponibilidade do produto, maior é a intenção de compra de tomates orgânicos dos consumidores pesquisados.

Utilizando também a TCP, Tarkiainen e Sundqvist (2005) pesquisaram o comportamento de consumidores pão e farinha orgânica na Finlândia. Os autores aplicaram a técnica de modelagem por equações estruturais para entender a relação entre as normas subjetivas, atitudes e intenções de compra do consumidor de alimentos orgânicos. O modelo proposto pelos autores mostrou-se consistente identificando que, no contexto do consumo de alimentos orgânicos, as normas subjetivas diferem daquelas propostas pela teoria original.

Shepherd, Magnusson e Sjödén (2005) realizaram uma survey na Suécia com 2.00o respondentes entre I8 e 65 anos de idade. Foram questionados os critérios de compra dos consumidores e as crenças que tinham a respeito dos alimentos orgânicos. Os resultados mostraram que apesar dos consumidores apresentarem atitudes positivas em relação a esse tipo de produto, esta atitude positiva não interfere diretamente na compra propriamente dita. Apesar dos entrevistados considerarem que o alimento orgânico é saudável, foi colocado que o preço de venda deveria ser o mesmo dos alimentos convencionais. Os consumidores também apontaram que o sabor do orgânico não representa um diferencial na escolha do mesmo, contudo, o alimento orgânico é citado como que preserva o meio ambiente em termos de não usar insumos químicos e poluentes.

Buscando-se identificar o perfil do consumidor de alimento orgânico, Krischke e Tomiello (2009), em pesquisa desenvolvida em Florianópolis-SC, apontam que: (a) 34\% têm entre 3I a 4 O anos de idade; (b) as mulheres são as que mais procuram pelo alimento orgânico (66\%); e (3) 5\%\% dos consumidores possuem terceiro grau completo.

Mesmo sendo um assunto que recebe relativa atenção dos meios de comunicação e dos governos, a maioria dos consumidores de alimentos não orgânicos não define corretamente o que venha a ser esse tipo de produto (KRISCHKE; TOMIELLO, 20o9; MENEZES; PADULA; CALLEGARO, 2007). Considerando-se exclusivamente o grupo de consumidores de alimentos orgânicos, o conhecimento sobre o significado deste tipo 
de alimento é maior, contudo, encontra-se uma quantidade significativa de pessoas que não entendem o conceito correto do produto. Como exemplo, pode-se destacar a pesquisa de Krischke e Tomiello (2009), na qual apenas 42,9\% dos consumidores entrevistados informaram que conhecem a definição de agricultura orgânica.

Apesar dessa realidade onde o conhecimento a respeito dos alimentos orgânicos ainda é incipiente no Brasil, a agricultura orgânica no país cresce a uma taxa de $20 \%$ (ZAMBERLAN; BÜTTENBENDER; SPAREMBERGER, 2OO6).

\section{Aspectos Metodológicos}

A pesquisa deste trabalho é de cunho qualitativo, classificada como exploratória, pois o seu objetivo está em fornecer um grau de aprofundamento sobre o problema de pesquisa (MARCONI; LAKATOS, 2009). Para Collis e Hussey (2005, p. 24) "[...] o objetivo da pesquisa exploratória é procurar padrões, idéias ou hipóteses, em vez de testar ou confirmar uma hipótese”. Considerou-se esse tipo de pesquisa ao empreender o estudo devido ao fato de existirem poucos estudos publicados referentes ao comportamento dos consumidores de alimentos orgânicos no Brasil. O método de coleta de dados utilizado foi grupos focais, a técnica empregada foi a análise de conteúdo, a qual utiliza observações geradas de entrevistas e coleta de documentos (BARBOUR, 2009; BARDIN, I977).

O grupo focal - ou focus group - é um tipo de entrevista grupal no qual o pesquisador ou moderador tem o papel de coordenar e dirigir o encontro com os entrevistados, conduzindo por meio de questões pré-estruturadas uma proposta exploratória de estudo (DENZIN; LINCOLN, I994; MALHOTRA, 2006).

Nesta pesquisa foram realizados dois grupos focais, sendo um com sete consumidores de alimentos orgânicos (GFA) e o outro com seis consumidores de alimentos orgânicos e que não utilizam alimentos orgânicos (GFB). O objetivo de se utilizar dois grupos focais diferentes foi de comparar e verificar o conhecimento sobre o alimento orgânico e suas características junto aos consumidores e aos não consumidores do produto investigado.

As entrevistas ocorreram no período de maio e junho de 20II. Tanto no GFA quanto no GFB foi redigido um termo de livre consentimento e autorização de dados, voz 
e imagem aos participantes, o que possibilitou a filmagem, gravação de voz e coleta de dados sócio-econômicos de todos os consumidores convidados (BARBOUR, 2009). Utilizou-se um questionário sócio-econômico que foi preenchido pelos próprios participantes com o objetivo de coletar dados para descrever a amostra.

A cidade de Juiz de For (MG) foi escolhida para a realização dos grupos focais devido à conveniência dos pesquisadores, por ser a cidade onde mora, e devido a existência de um local apropriado para o desenvolvimento dos trabalhos.

Os dois tipos de consumidores foram selecionados aleatoriamente por meio de parceria com varejos especializados - seis varejos que comercializam alimentos orgânicos em Juiz de Fora (MG). Os varejistas convidavam clientes para participar de uma pesquisa na Universidade Federal de Juiz de Fora (UFJF), os consumidores que aceitavam o convite repassavam o nome e telefone de contato para o varejista, que posteriormente encaminhava esses dados para os pesquisadores entrarem em contato com os clientes e agendarem as entrevistas.

Para esta pesquisa, conforme sugestão de Barbour (2009), foi preparado um roteiro específico para cada um dos dois grupos focais. De acordo com Oliveira e Freitas (2008, p. 337) “o roteiro deverá ser preparado a partir de uma lista de questões a serem respondidas, as quais deverão ser organizadas em grupos de tópicos e ordenadas em uma sequência lógica”. Quanto às questões elaboradas, foram destacados temas-chaves relativos à pesquisa. Neste contexto, utilizou-se: hábito de consumo; conhecimentos relacionados aos alimentos orgânicos; tipo de alimento consumido; percepções a cerca da qualidade dos alimentos; influência de pessoas conhecidas no hábito de consumidor alimentos; dentre outras.

Para a análise dos dados utilizou-se a análise de conteúdo. Para Stone, Dunphy e Kirsch (I970) esta é uma técnica que permite fazer inferências, identificando objetivamente as características da mensagem. Para Chizzotti (2006) na análise de conteúdo a frequência com que aparece no texto palavras e termos propiciam a criação de categorias, sendo que estas devem ser pertinentes aos objetivos da pesquisa. Para o autor, as unidades vocabulares podem ser também reunidas segundo um tema. Seguindo esta visão, a presente pesquisa para desenvolver a análise de conteúdo focou o tema: alimento orgânico e saúde? Além deste tema, a análise de conteúdo apontou as palavras e 
termos frequentes, os quais foram selecionados e agrupados em torno das seguintes categorias: (a) termos: saúde, alimentação, qualidade de vida; (b) valores: humanos, econômicos; e (c) opinião: favorável, desfavorável.

Antes da tabulação foi desenvolvido um relatório com a transcrição das falas dos dois grupos focais, o que possibilitou o cruzamento de dados com as gravações e imagens geradas, possibilitando também a identificação das categorias já citadas anteriormente.

\section{Análise dos Dados}

A TAB. I apresenta a frequência das palavras mais citadas pelos participantes do grupo focal com consumidores de alimentos orgânicos (GFA). A categorização possibilitou a identificação de 65 termos/palavras do GFA, contudo, na TAB. I foram elencados os io principais termos/palavras.

Tabela I - Frequência de palavras/termos no GFA

\begin{tabular}{llc}
\hline & \multicolumn{1}{c}{ PALAVRAS - TERMOS } & FREQUENCIA \\
\hline 1 & Hábito de consumo pelo alimento orgânico & 53 \\
2 & Importância dos pequenos produtores de orgânicos & 13 \\
3 & Necessidade de certificação de alimento orgânico & 12 \\
4 & Alimento orgânico faz bem à saúde & 12 \\
5 & Importância de se ter varejo/acesso/sortimento de orgânico & 12 \\
6 & O hábito do alimento orgânico envolve uma cultura própria & 11 \\
7 & Hábito de consumo de açúcar orgânico & 9 \\
8 & Necessidade de conhecer mais sobre o alimento orgânico & 8 \\
9 & O preço do alimento orgânico é elevado (caro) & 8 \\
10 & A cultura do alimento orgânico envolve respeito ao próximo/amizade & 8 \\
\hline
\end{tabular}

Fonte: Dados da pesquisa.

Com relação à frequência de termos/palavras usadas no GFA, observa-se que o hábito de consumo pelo alimento orgânico foi o mais citado pelos participantes $(\mathrm{f}=53)$, seguido de importância dos pequenos produtores de orgânicos $(\mathrm{f}=\mathrm{I} 3)$, necessidade de certificação de alimento orgânico $(\mathrm{f}=\mathrm{I} 2)$, alimento orgânico faz bem à saúde $(\mathrm{f}=\mathrm{I} 2) e$ importância de se ter varejo/acesso/sortimento de orgánico $(\mathrm{f}=\mathrm{I} 2)$.

No caso do termo hábito de consumo pelo alimento orgánico, a mesma foi citada pelos participantes no sentido de apontar a preferência por este tipo de alimento e por conhecer os benefícios que o produto traz à saúde humana. 
Por meio da análise da frequência das palavras e termos do GFA, pode-se inferir que o consumidor de alimento orgânico que participou da pesquisa preocupa-se com: (a) o conceito de alimento orgânico; (b) com quem produz o alimento orgânico; (c) com a qualidade deste alimento; (d) com o bem que o produto faz à saúde; e (e) com o acesso ao varejo e ao sortimento que pode ser melhor. Os alimentos orgânicos mais citados pelos participantes do GFA foram: açúcar, verduras, achocolatados e arroz integral. Para os entrevistados, no Brasil os alimentos orgânicos certificados não são encontrados com facilidade nos varejos.

Eu acho que falta tudo (referindo-se ao alimento orgânico) no varejo [...] como nutricionista eu indico o alimento orgânico [...] aí as pessoas perguntam pra mim, onde eu encontro isso (alimento orgânico)? Eu até já comecei um projeto de um site informando sobre 0 alimento orgânico, onde nele ia colocar os pontos de venda, mas é muito complicado [...] (Entrevistado I ${ }^{5}$.

Os participantes citam também a falta de conhecimento das pessoas e dos empregados dos varejos com relação ao conceito do alimento orgânico, suas características, bem como a localização/disposição do produto no varejo.

Aí a gente pergunta: ô moço, tem café orgânico? Aí ele (empregado do varejo) responde: o que é orgânico mesmo? A gente vai ao mercado e pergunta sobre um alimento orgânico e ninguém sabe o que é orgânico. (Entrevistado 2).

Falta informação. Eles (empregados dos varejos) não sabem o que é orgânico (Entrevistado 3).

Os participantes do GFA comentaram que procuram por alimentos orgânicos como: frutas, legumes, verduras, massas, pães, açúcar, geléias, sucos prontos, biscoitos, café, carne de boi, dentre outros. Tal fato pode ser observado em seus relatos:

O que a gente costuma mais consumir é o pão integral, que vem de Petrópolis, ele é IOO\% orgânico, e 0 açúcar da marca $X^{6}$ que é muito diferente do que se compra aí fora, ele adoça muito mais [...] suco de uva, geléia [...] (Entrevistado 2).

Eu consumo bastante industrializado orgânico, porque eu trago muito de fora, ou do Rio ou de BH, achocolato meu é orgânico, açúcar é orgânico, mistura pra bolo pronta, mistura pra pão de queijo, pão de forma eu não compro tanto porque não dura tanto, biscoito de Itaipava que é muito bom, têm bolos caseiros também, torradas, geléias um monte, café, estes tipos de alimento orgânico eu tenho mais facilidade, já a carne é mais difícil de encontrar e é muito caro porque chega a $\mathrm{R} \$ 6 \mathrm{O}$,oo reais o quilo (Entrevistado I).

\footnotetext{
${ }^{5}$ Como a metodologia de grupo focal prima pela análise da opinião do grupo de entrevistados, e não de indivíduos, optouse por não identificar os respondentes por seus respectivos nomes.

6 Optou-se por não citar as marcas mencionadas pelos participantes da pesquisa.
}

Revista Administração em Diálogo

ISSN 2178-0080

Programa de Estudos Pós-Graduados em Administração

Pontifícia Universidade Católica de São Paulo 
Eu já costumo consumir poucos alimentos industrializados, como açúcar e geléias, porque o alimento orgânico é mais caro, acho porque o consumo ainda é baixo [...] (Entrevistado 4).

O Entrevistado I ainda comentou que nas viagens ao exterior traz alimentos orgânicos que no Brasil são mais caros ou não são encontrados. Tanto na gravação de voz e vídeo, como na observação dos participantes, verificou-se que os presentes adotam o alimento orgânico também como uma "filosofia de vida”, pois eles preocupam-se com a alimentação e também com a educação, preservação da natureza e com qualidade de vida.

O consumidor de alimento orgânico resgata a amizade. Tem uma relação de confiança (Entrevistado 5).

Aqueles (consumidores de alimentos orgânicos) que são doidos pelo orgânico não consomem plástico. Eles já levam a caixinha de papelão e a sacola biodegradável. Agora, tem aqueles (consumidores de alimentos não orgânicos) que preferem a sacola plástica para levar os alimentos (Entrevistado 6).

Os participantes reclamaram da localização dos produtos orgânicos no varejo. Eles citam que o alimento orgânico não tem local específico como outros produtos no layout do varejo. Para os consumidores do GFA, os alimentos orgânicos são em muitos casos misturados com outros tipos de alimentos, como os light e diet.

A respeito do espaço nos mercados que oferecem alimento orgânico; eu acho muito ruim em Juiz de Fora, nota zero [...] chega ao mercado $X$ lá não tem espaço específico para o produto orgânico, pois tem a marca $Y$ de alimento orgânico que logo é misturada a outra marca que não tem nada de orgânico [...]. No mercado o produto orgânico é misturado com outros produtos. Fica difícil de encontrar o orgânico (Entrevistado 2).

Tem que buscar, procurar (produto orgânico) [...]. Nós (consumidores de alimentos orgânicos) como grãozinhos de arroz a gente tenta construir, mostrar o que é orgânico [...] (Entrevistado I).

Indagados pelo moderador sobre quais as características mais importantes dos alimentos orgânicos, os participantes apontaram pela ordem: (i) saúde; (ii) qualidade de vida/bem-estar/estilo de vida; e (iii) respeito ao meio ambiente/respeito ao próximo/respeito ao ecossistema.

A principal característica que o alimento orgânico proporciona é a saúde (Entrevistado I).

Concordo. Por que você muda seu padrão de vida (quando se retrata à qualidade de vida) (Entrevistado 2).

Qualidade de vida eu acho que é a segunda coisa (Entrevistado 2). 
Se começa a interessar por outras pessoas, outros esportes, outras coisas [...] interesse pelo ecossistema, rios [...] (Entrevistado I).

Eu acho que é o respeito ao ser humano, às pessoas (se referindo à outra característica do alimento orgânico) (Entrevistado 5).

Com relação ao grupo focal com não consumidores de alimentos orgânicos (GFA) foram transcritas um número maior termos do que no GFA. Enquanto que o segundo apresentou 65 termos, o GFB citou 77 .

Os produtos mais citados pelos participantes do GFB foram o doce o café, o pão e o açúcar. Os participantes desse grupo demonstraram desconhecimento sobre o significado de alimento orgânico, que foi definido como aquele tipo de alimento que não possui agrotóxico.

A frequência dos dez principais termos do GFB pode ser acompanhada na TAB.

2.

Tabela 2 - Frequência de palavras/termos no GFB

\begin{tabular}{ccc}
\hline & PALAVRAS - TERMOS & FREQUENCIA \\
\hline 1 & Problemas de saúde com alta taxa de colesterol & 16 \\
2 & Hábito de consumo pelo doce tradicional & 10 \\
3 & A troca da marca de um alimento ocorre quando o preço é elevado & 8 \\
4 & Hábito de consumo pelo café tradicional & 7 \\
5 & Falta de conhecimento sobre alimento orgânico & 7 \\
6 & Confiança nas informações de embalagens quando se trata de alimento orgânico & 6 \\
7 & Desconhecem o que seja alimento transgênico & 6 \\
8 & Hábito de consumo pelo leite desnatado tradicional & 5 \\
9 & Hábito de consumo pelo pão light integral tradicional & 5 \\
10 & Hábito de consumo pelo açúcar tradicional & 5 \\
\hline
\end{tabular}

Fonte: Dados da pesquisa.

No GFB problemas de saúde com alta taxa de colesterol $(\mathrm{f}=\mathrm{I} 6)$ foi o termo mais frequente, seguido por hábito de consumo pelo doce tradicional $(\mathrm{f}=\mathrm{IO})$, a troca da marca de um alimento ocorre quando o preço é elevado $(\mathrm{f}=8)$, hábito de consumo pelo café tradicional $(f=7)$ e falta de conhecimento sobre alimento orgânico $(f=7)$. Além destes termos mais frequentes, tiveram também destaque nas falas dos participantes do GFB assuntos relativos à alimentação rápida feita em lanchonetes, sendo que os entrevistados afirmaram que consomem alimentos mais gordurosos, geralmente fritos, que são oferecidos a preços menores.

Nos momentos iniciais da sessão do GFB, os participantes destacaram em suas falas também os problemas relacionados à saúde, ora originados por hereditariedade ora 
por uma alimentação pouco saudável. As doenças apontadas pelos consumidores foram em relação à taxa colesterol elevado e à predisposição à hipertensão. Os entrevistados desse grupo consideram importante que se tenha uma alimentação mais saudável e que se pratiquem esportes com mais regularidade, mesmo não sendo esses hábitos da maioria desses participantes Essas preocupações podem sugerir que mesmo não conhecendo o real significado de um alimento orgânico, os entrevistados do GFB identificam o produto como algo mais saudável e benéfico à saúde.

Eu como pouco. Eu tenho colesterol alto mais acho que também é hereditário (Entrevistado 7).

Eu também tenho colesterol alto (Entrevistado 8).

Eu evito comer coisas muito salgadas porque eu tenho predisposição a ter hipertensão porque a minha família inteira praticamente tem [...] eu até prefiro arroz integral [...] (Entrevistado 9).

Eu não estou jantando mais, estou tomando medicamento $\mathrm{X}$ para tirar a ansiedade (Entrevistado Io).

Outro dado verificado no GFB foi de que os participantes estão dispostos a se alimentarem de orgânicos, contudo, o preço mais alto representa uma barreira. Mesmo assim, os participantes afirmaram que pagariam até $20 \%$ a mais por um alimento orgânico.

É claro que eu optaria em comprar alimento orgânico se ele fosse um pouco mais barato. Eu optaria por uma verdura mais saudável né! (Entrevistado Io).

Eu acho que eu optaria sim. No princípio poderia até estranhar um pouco o gosto, mas depois acostuma rápido. É que o sabor é um pouco diferente (Entrevistado II).

Eu optaria, mas vai depender do preço. Uns $20 \%$ a mais eu pagaria pelo orgânico. Acima disso, depende do tipo do alimento orgânico (Entrevistado 8).

Apesar de se encontrar diferenças de comportamento e pensamento entre os participantes dos dois grupos focais realizados, em ambos os participantes identificaram uma necessidade de conhecer melhor os alimentos orgânicos.

Em relação ao perfil sócio-econômico, comparando os dois grupos focais, os participantes do GFA possuem renda familiar superior aos participantes do GFB, o que vem a corroborar com outras pesquisas já realizadas sobre consumo de alimento orgânico (COLTRO, 20o6; KRISCHKE; TOMIELLO, 2009). 
Dos sete participantes do GFA, apenas um está cursando o ensino superior, sendo que dois possuem curso de mestrado completo, um apresenta curso de especialização completo e outros três já concluíram o ensino superior (TAB. 3).

Tabela 3 - Perfil sócio-econômico dos consumidores de alimentos orgânicos

\begin{tabular}{|c|c|c|c|c|c|c|}
\hline & GÊNERO & $\begin{array}{c}\text { FAIXA } \\
\text { ETÁRIA }\end{array}$ & $\begin{array}{c}\text { RENDA } \\
\text { FAMILIAR }\end{array}$ & PROFISSÃO & ESCOLARIDADE & $\begin{array}{c}\text { ESTADO } \\
\text { CIVIL }\end{array}$ \\
\hline 1 & M & $\begin{array}{l}\text { Acima de } \\
50 \text { anos }\end{array}$ & $\begin{array}{l}\text { Até } 04 S^{*} \\
\mathrm{R} \$ 2.180,00\end{array}$ & $\begin{array}{c}\text { Produtor rural e } \\
\text { professor } \\
\text { aposentado }\end{array}$ & Mestrado completo & Casado \\
\hline 2 & $M$ & $\begin{array}{c}26 \text { a } 30 \\
\text { anos }\end{array}$ & $\begin{array}{l}\text { Até } 07 \text { SM } \\
\mathrm{R} \$ 3.815,00\end{array}$ & Professor & Mestrado completo & Solteiro \\
\hline 3 & $F$ & $\begin{array}{c}21 \text { a } 25 \\
\text { anos }\end{array}$ & $\begin{array}{l}\text { Até } 04 \text { SM } \\
\mathrm{R} \$ 2.180,00\end{array}$ & $\begin{array}{l}\text { Estudante e } \\
\text { comerciante }\end{array}$ & $\begin{array}{l}\text { Ensino superior } \\
\text { incompleto }\end{array}$ & Solteira \\
\hline 4 & $\mathrm{~F}$ & $\begin{array}{l}\text { Acima de } \\
50 \text { anos }\end{array}$ & $\begin{array}{l}\text { Até } 04 \text { SM } \\
\mathrm{R} \$ 2.180,00\end{array}$ & $\begin{array}{l}\text { Assistente social } \\
\text { aposentada }\end{array}$ & $\begin{array}{l}\text { Ensino superior } \\
\text { completo }\end{array}$ & Casada \\
\hline 5 & $\mathrm{~F}$ & $\begin{array}{c}26 \text { a } 30 \\
\text { anos }\end{array}$ & $\begin{array}{l}\text { Até } 15 \mathrm{SM} \\
\mathrm{R} \$ 8.125,00\end{array}$ & Nutricionista & $\begin{array}{l}\text { Especialização } \\
\text { completa }\end{array}$ & Solteira \\
\hline 6 & $\mathrm{~F}$ & $\begin{array}{c}36 \text { a } 40 \\
\text { anos }\end{array}$ & $\begin{array}{l}\text { Até } 20 \text { SM } \\
\text { acima de } \\
\mathrm{R} \$ 10.900\end{array}$ & $\begin{array}{c}\text { Administradora e } \\
\text { contadora }\end{array}$ & $\begin{array}{l}\text { Ensino superior } \\
\text { completo }\end{array}$ & Casada \\
\hline 7 & $\mathrm{~F}$ & $\begin{array}{l}\text { De } 46 \text { a } \\
50 \text { anos }\end{array}$ & $\begin{array}{l}\text { Até } 15 \mathrm{SM} \\
\mathrm{R} \$ 8.125,00\end{array}$ & Bióloga & $\begin{array}{l}\text { Ensino superior } \\
\text { completo }\end{array}$ & Casada \\
\hline
\end{tabular}

Ao verificar o segundo grupo focal, observa-se que o nível de escolaridade é inferior ao grupo focal dos consumidores do GFA - TAB. 4 .

Tabela 4 - Perfil sócio-econômico dos não consumidores de alimentos orgânicos

\begin{tabular}{|c|c|c|c|c|c|c|}
\hline & GÊNERO & $\begin{array}{c}\text { FAIXA } \\
\text { ETÁRIA }\end{array}$ & $\begin{array}{c}\text { RENDA } \\
\text { FAMILIAR }\end{array}$ & PROFISSÃO & ESCOLARIDADE & $\begin{array}{c}\text { ESTADO } \\
\text { CIVIL }\end{array}$ \\
\hline 1 & M & $\begin{array}{l}\text { Acima de } \\
50 \text { anos }\end{array}$ & $\begin{array}{l}\text { Até } 10 \mathrm{SM}^{*} \\
\mathrm{R} \$ 5.450,00\end{array}$ & Militar reformado & $\begin{array}{l}\text { Ensino médio } \\
\text { completo }\end{array}$ & Casado \\
\hline 2 & M & $\begin{array}{l}\text { De } 21 \text { a } \\
25 \text { anos }\end{array}$ & $\begin{array}{l}\text { Até } 03 \mathrm{SM} \\
\mathrm{R} \$ 1.635,00\end{array}$ & Estudante & $\begin{array}{l}\text { Ensino superior } \\
\text { incompleto }\end{array}$ & Solteiro \\
\hline 3 & $F$ & $\begin{array}{c}\text { Acima de } \\
50 \text { anos }\end{array}$ & $\begin{array}{l}\text { Até } 05 \text { SM } \\
\mathrm{R} \$ 2.725,00\end{array}$ & $\begin{array}{c}\text { Assistente social } \\
\text { e aposentada }\end{array}$ & $\begin{array}{l}\text { Ensino superior } \\
\text { completo }\end{array}$ & Separada \\
\hline 4 & $\mathrm{~F}$ & $\begin{array}{c}\text { Acima de } \\
50 \text { anos }\end{array}$ & $\begin{array}{l}\text { Até } 04 \text { SM } \\
\mathrm{R} \$ 2.180,00\end{array}$ & $\begin{array}{l}\text { Vendedora e } \\
\text { aposentada }\end{array}$ & $\begin{array}{l}\text { Ensino médio } \\
\text { completo }\end{array}$ & Casada \\
\hline 5 & $F$ & $\begin{array}{c}36 \text { a } 40 \\
\text { anos }\end{array}$ & $\begin{array}{l}\text { Até } 02 \text { SM } \\
\mathrm{R} \$ 1.090,00\end{array}$ & $\begin{array}{l}\text { Empregada } \\
\text { doméstica }\end{array}$ & $\begin{array}{l}\text { Ensino médio } \\
\text { incompleto }\end{array}$ & Casada \\
\hline 6 & $\mathrm{~F}$ & $\begin{array}{c}\text { Acima de } \\
50 \text { anos }\end{array}$ & $\begin{array}{l}\text { Até } 06 \text { SM } \\
\mathrm{R} \$ 3.270,00\end{array}$ & Advogada & $\begin{array}{l}\text { Ensino superior } \\
\text { completo }\end{array}$ & $\begin{array}{l}\text { União } \\
\text { estável }\end{array}$ \\
\hline
\end{tabular}

Fonte: Dados da pesquisa.

Nota: *Salário mínimo $(\mathrm{SM})$ referente ao mês de maio/2OII.

Legenda: $\mathrm{M}=$ masculino; $\mathrm{F}=$ feminino. 
Por fim, destaca-se que quanto ao gênero, do total de sete participantes do GFA, dois são homens (29\%) e cinco são mulheres (7ז\%). No GFB dois são homens (33\%) e quatro são mulheres $(67 \%)$ de um total de seis participantes

\section{Considerações Finais}

Nesta pesquisa, que teve como objetivo compreender o comportamento do consumidor brasileiro de alimentos orgânicos observou-se que os benefícios para a saúde são o principal motivo que leva os consumidores a adquirirem esse tipo de produto, mesmo eles não dominando de forma integral a definição de alimento orgânico. Na opinião dos entrevistados, o alimento orgânico possibilita uma melhor qualidade de vida baseada em um hábito alimentar considerado saudável, proporcionado pelo alimento orgânico.

Na pesquisa observou-se uma socialização que se forma entre os consumidores de alimentos orgânicos. Esse comportamento expressa-se no estabelecimento de cultura envolta das pessoas que consomem o alimento orgânico, pois, segundo relatos dos próprios consumidores, eles passam a estabelecer laços de amizade tendo em vista os hábitos relacionados às preocupações por uma vida saudável e por uma alimentação mais natural.

De acordo com os resultados encontrados, a diferença de preço entre os alimentos orgânicos e os tradicionais impacta consideravelmente na decisão de compra desse tipo de produto. Os participantes da pesquisa afirmaram estar dispostos a pagar até $20 \%$ a mais pelo alimento orgânico, contudo, percebe-se que essa diferença geralmente ultrapassa esse percentual. O que pode sugerir que uma diminuição nos preços impactaria em uma maior procura por esse tipo de alimento.

Outro dado apontado pelos entrevistados foi a falta de conhecimento do significado do alimento orgânico e de suas características, tanto por parte dos consumidores como por parte dos empregados dos varejos que ofertam este tipo de produto. Segundo os entrevistados, outro problema é que são poucos os locais onde é possível comprar alimentos orgânicos, sendo que nesses locais normalmente se encontra outro problema: a falta de um local de venda específico e bem sinalizado nos varejos. Assim, alguns dos participantes optam por adquirir esse tipo de produto em viagens para 
cidades maiores ou até mesmo para o exterior. Assim, infere-se que se o aumento do número de pontos de venda de alimentos orgânicos, relacionado a uma estratégia de merchandising adequada, pode possibilitar o aumento na compra de alimentos orgânicos.

De acordo com os grupos focais, corroborando com a teoria apresentada, podese elencar os seguintes motivos que levam os consumidores a se alimentarem dos orgânicos: o benefício à saúde, a qualidade de vida e a consciência de ser um indivíduo que respeita mais as pessoas e ao meio ambiente natural.

Acredita-se que a presente pesquisa contribui para a área acadêmica no sentido de resgatar um referencial teórico atualizado sobre o comportamento do consumidor de alimentos orgânicos. Além desta contribuição, o estudo traz a tona o comportamento consumidor brasileiro de alimentos orgânicos, o qual se tem poucas pesquisas a respeito. Ainda destaca-se o caráter exploratório da pesquisa, no qual foram realizados dois grupos focais com diferentes tipos de consumidores de alimentos, o qual pode vir a fundamentar estudos quantitativos a respeito do tema.

Como contribuição gerencial, a pesquisa sugere a necessidade de se reforçar o conceito de alimento orgânico e seus benefícios, o que pode ser útil na política de comunicação com o mercado das organizações que lidam com esse tipo de produto. $\mathrm{O}$ estudo aborda informações de precificação, de distribuição e de merchandising referente aos alimentos orgânicos que podem ser úteis para orientar os profissionais de marketing.

Com o objetivo de empreender novos estudos sobre o tema, sugere-se que a partir das categorizações aqui identificadas sejam desenvolvidas pesquisas quantitativas para analisar o impacto de cada uma nelas no comportamento desse tipo de consumidor. Ademais, também sugere-se o desenvolvimento de outros grupos focais em diferentes cidades e regiões do país, buscando-se assim entender e identificar as diferenças do pensamento dos consumidores dessas regiões. Por fim, outra opção de estudo é a investigação de diferentes segmentos sócio-econômicos, buscando-se melhor compreender o impacto dessas variáveis econômicas e sociais no hábito de se consumir alimentos orgânicos. 


\section{Referências}

ABRAS (Associação Brasileira de Supermercados). 20I2. Disponível em:

$<$ http://www.abrasnet.com.br/economia-e-pesquisa/consumidor/>. Acesso: I4 mar. $20 \mathrm{OI}$.

AMA (American Marketing Association). 2012. Disponível em:

$<$ http://www.marketingpower.com/_layouts/Dictionary.aspx?dLetter=C\#consumer+behavior $>$. Aceso: I7 mar. 2012.

AJZEN, I. The theory of planned behavior. Organizational behavior and human decision process, n. 5O, p. I79-2II, I99I.

ARCHANJO, L. R.; BRITO, K. F. W.; SAUERBECK, S. Alimentos orgânicos em Curitiba: consume e significado. Revista Caderno de Debates, Núcleo de Estudos e Pesquisas em Alimentação da UNICAMP, v. 8, 200 I.

BAGOZZI, R. P.; GÜRHAN-CANLI, Z.; PRIESTER, J. R. The social psychology of consumer behavior. Buckingham: Open University Press, 2002.

BARBOUR, R. Grupos Focais. Porto Alegre: Artmed, 2009.

BARDIN, L. Análise de conteúdo. Lisboa: Edições 70, I977.

BLACKWELL, R. D.; MINIARD, P. W.; ENGEL, J. F. Comportamento do consumidor. São Paulo: Pioneira Thomson Learning, 2005.

CESCHIM, G.; MARCHETTI, R. Z. O comportamento inovador entre consumidores de produtos orgânicos: uma abordagem qualitativa. In: Encontro Nacional da Associação Nacional de PósGraduação e Pesquisa em Administração, 33, 2009, São Paulo. Anais... São Paulo: ANPAD, 2009.

COLLIS, J.; HUSSEY, R. Pesquisa em administração: um guia prático para alunos de graduação e pós-graduação. 2 ed. Porto Alegre: Bookman, 2005.

CUPERSCHMID, N. R. M.; TAVARES, M. C. Atitudes em Relação ao Meio Ambiente e sua Influência no Processo de Compra de Alimentos. RIMAR - Revista Interdisciplinar de Marketing, v.I, n.3, p. 5-I4, set./dez. 2002.

CHIZZOTTI, A. Pesquisa qualitativa em ciências humanas e sociais. Petrópolis-RJ: Vozes, 2006.

COLTRO, A. O comportamento do consumidor consciente como fonte de estímulos de mercado às ações institucionais sócio-ambientais. IN: I SEMINÁRIO SOBRE SUSTENTABILIDADE, 2006, CURITIVA - PR. Anais... Curitiba - PR: Centro Universitário FAE, 2006.

DEFRA (Department for environment food and rural affairs). 20II. Disponível em: <http://ww2.defra.gov.uk/> Acesso: O5 abr. 20II.

DENZIN, N. K.; LINCOLN, Y. S. Handbook of qualitative research. Thousand: Sage Publications, I994.

DEY, I. Qualitative data analysis: a user-friendly guide for social scientists. London \& New York: Routledge Taylor e Francis Group, 2005.

ENGEL, J. F.; BLACKWELL, R. D.; MINIARD, P. W. Consumer Behavior. The Dryden Press, I993.

ENGEL, J. F.; KOLLAT, D. T.; BLACKWELL, R. D. A model of consumer motivation and behavior. In: Consumer behavior. New York: Holt, Rinehart and Winston, I968. 
FIBL (Research Institute of Organic Agriculture). Activity Report 2008. Disponível em: $<$ http://www.FIBL.org/en/about-us/activity-report.html>. Acesso: I7 mar. 2 OII.

FISHBEIN, M.; AJZEN, I. Belief, attitude, intention and behavior: an introduction to theory and research. Reading Massachussets: Adison - Wesley, I975.

HAWKINS, D.; MONTHERSBAUGH, L.; BEST, R. J. Comportamento do consumidor: construindo a estratégia de marketing. Rio de Janeiro: Elsevier, 2007.

HOPPE, A.; BARCELLOS, M. D.; VIEIRA, L. M.; MATOS, C. A. Comportamento do Consumidor de Produtos Orgânicos: uma aplicação da Teoria do Comportamento Planejado. In: Encontro Nacional da Associação Nacional de Pós-Graduação e Pesquisa em Administração, 34, 2OIO. Anais... Rio de Janeiro: ANPAD, 2010.

IFOAM (International Federation of Organic Agriculture). 20IO. Disponível em: <http://www.ifoam.org/growing_organic/definitions/sdhw/pdf/DOA_Portuguese.pdf>. Acesso: 29 dez. 2 OIO.

KRISCHKE, P. J.; TOMIELLO, N. O comportamento de compra dos consumidores de alimentos orgânicos: um estudo exploratório. Cadernos de Pesquisa Interdisciplinar de Cièncias Humanas, Universidade Federal de Santa Catarina (UFSC), v. IO, n. 96, p. 27-43, 2009.

MALHOTRA, N. Pesquisa de marketing: uma orientação aplicada. 4. ed. Porto Alegre: Bookman, 2006.

MARCONI, M. de A.; LAKATOS, E. M. Técnicas de pesquisa: planejamento e execução de pesquisas, amostragens e técnicas de pesquisa, elaboração, análise e interpretação de dados. 7. Ed. São Paulo: Atlas, 2009.

MENEZES, D. C.; PADULA, A. D.; CALLEGARO, C. A. M. Internacionalização da oferta de vinho orgânico: um estudo sobre os valores pessoais e motivações de compra entre consumidores internacionais. IN: II ENCONTRO DE ESTUDOS EM ESTRATÉGIA - ANPAD, 3, 2007. Anais... São Paulo: ANPAD, 2007.

MORGAN, D. L. Focus group as qualitative research. Sage university paper series. In: Qualitative research methods. Newbury Park: Sage Publications, 1988.

MOWEN, J.; MINOR, M. S. Comportamento do consumidor. São Paulo: Prentice Hall, 2003.

OLIVEIRA, M.; FREITAS, H. Focus group, pesquisa qualitativa: resgatando a teoria, instrumentalizando o seu planejamento. RAUSP, v. 33, n. 3, p. 83-91, jul/set., 1998.

ORGANIC MONITOR. 2OII. Disponível em: <http://www.organicmonitor.com/> . Acesso em: 20 Jul. 2OII.

PENTEADO, S. R. Introdução à agricultura orgânica. Viçosa-MG: Aprenda fácil, 2003.

PETER, J. P.; OLSON, J. C. Comportamento do consumidor e estratégia de marketing. 8. ed. São Paulo: McGraw-Hill, 2009 .

PIMENTA, M. L.; VILAS BOAS, L. H. B. Percepção de consumidores de alimentos orgânicos na cidade de Uberlândia na perspectiva de valores: uma aplicação da laddering e cadeia de meios e fins. IN: III ENCONTRO DE MARKETING EMA - ANPAD, 20o8. Curitiba. Anais... Curitiba: ANPAD. CD-ROM. 
PIMENTA, V. P.; SENA, J. O. A.; MOURA, L. P. P; CUNHA, F. A. D.; RUPP, L. M.; HISANO, L. K.; CALDAS, R, G.; FREITAS, I. D.; VIEIRA, D. T. Percepção dos consumidores quanto aos produtos orgânicos na região de Maringá, Paraná, Brasil. Revista Brasileira de Agroecologia, v. 9, n. 2, nov. 2009 .

RUCINSKI, J.; BRANDENBURG, A. Consumidores de orgânicos em Curitiba. IN: I ENCONTRO DA ASSOCIAÇı̃̃O NACIONAL DE PÓS-GRADUAÇÃO EM AMBIENTE E SOCIEDADE, I, 2002. Anais... Indaiatuba-SP: ANPPAS, 2002.

SHEPHERD, R.; MAGNUSSON, M.; SJÖDÉN, Per-Olow. Determinants of consumer behavior related to organic foods. Ambio, v. 34, n. 4-5, p. 352-359, 2005.

SMITH, T. A.; LIN, B-H; HUANG, C. L. Growth and development in the U.S. retail organic food sector. Sustainability, v. I, p. 573-59I, sept., 2009.

SOARES, W. L. Uso dos agrotóxicos e seus impactos à saúde e ao ambiente: uma avaliação integrada entre a economia, a saúde pública, a ecologia e a agricultura. Tese. (Doutorado em Ciências de Saúde Pública e Meio Ambiente) - Escola nacional de Saúde Pública (ENSP/FIOCRUZ). Rio de Janeiro: FIOCRUZ, 2OIO.

SOLOMON, M. R. O comportamento do consumidor: comprando, possuindo e sendo. 5 . ed. Porto Alegre: Bookman, 2002.

STEFANO, N.; GODOY, L. P.; RUPPENTHAL, J. E. Uma análise reflexiva do comportamento dos consumidores de produtos orgânicos. In: Simpósio Em Engenharia de Produção, I4, 2007. Anais... Bauru-SP: SIMPEP, 2007.

STEWART, D.; W. SHAMDASANI, P. N. Focus group: theory and practice. Applied Social Research Methods Series. v. 2o. California-USA: Sage Publications, I99O.

STONE, P. J.; DUNPHY, D. C.; KIRSCH, J. The general inquirer: a computer approach to content analysis. Cambridge, MA: Harvard University Press, ,970.

TARKIAINEN, A.; SUNDQVIST, S. Subjective norms, attitudes and intentions of Finnish consumers in buying organic food. British Food Journal, v. IO7, n. II, p. 808-822, 2005.

VILAS BOAS, L. H. B; SETTE, R. S.; BRITO, M. J. de. Comportamento do consumidor de produtos orgânicos: uma aplicação da teoria da cadeia de meios e fins. Organizações Rurais \& Agroindustriais, Lavras, v. 8, n. I, p. 25-39, 2006.

WILLIAMSON, C. S. Is organic food better for our health? British Nutrition Foundation, Nutrition Bulletin, n. 32, p. 104-IO8, 2007.

ZAMBERLAN, L.; BÜTTENBENDER, P. L.; SPAREMBERGER, A. IN: XVII ENCONTRO NACIONAL DA ASSOCIAÇÃO NACIONAL DE PÓS-GRADUAÇÃO E PESQUISA EM ADMINISTRAÇÃO, 3o, 2006. Anais... Salvador- BA: ANPPAS, 2006. 